\title{
Experiencia de aprendizaje-servicio (ApS) solidario en el grado de Español: Estudios Lingüísticos y Literarios de la Universidad de A Coruña
}

\author{
Veleiro, Ana
}

Profesora titular de escuela universitaria, Facultad de Filología (UDC)

\section{RESUMEN}

La aplicación en materias universitarias de la metodología pedagógica denominada aprendizaje-servicio (en adelante, ApS) favorece que los alumnos adquieran competencias transversales que hasta el momento no se trabajan suficientemente. Comencé poniéndola en práctica en una de las líneas del trabajo de fin de grado propuestas por la Facultad de Filología de la Universidad de A Coruña (UDC), la de «Español como lengua extranjera» (en adelante, ELE), que se centra en cuestiones metodológicas de dicho ámbito y en la que se incluyen propuestas docentes y otros aspectos relacionados con el aprendizaje y la enseñanza de ELE. Una de mis alumnas aceptó el reto de diseñar y poner en práctica una unidad didáctica con adultos inmigrantes en una ONGD coruñesa, Ecodesarrollo Gaia. Son muchos Ios resultados obtenidos en esta aplicación del ApS: desde la mejora en el arraigo sociolaboral de los inmigrantes hasta la consecución de la finalidad esencial de nuestra Universidad, esto es, la de ser «un servicio público de calidad orientado a conseguir mayores niveles de bienestar para el conjunto de la sociedad....'.

PALABRAS CLAVE: aprendizaje-servicio; español para inmigrantes; enseñanza del español para fines específicos; enseñanza del español como segunda lengua (EL2). 


\section{CITA RECOMENDADA:}

Veleiro Pérez, A.M. (2018). Experiencia de aprendizaje-servicio (ApS) solidario en el grado de Español: Estudios Lingüísticos y Literarios de la Universidad de A Coruña. En E. de la Torre Fernández (ed.) (2018). Contextos universitarios transformadores: retos e ideas innovadoras. II Xornadas de Innovación Docente. Cufie. Universidade da Coruña (pág. 225-242).

DOI capítulo: https://doi.org/10.17979/spudc.9788497496780.225

DOI libro: https://doi.org/10.17979/spudc.9788497496780

\section{ABSTRACT}

The application in university subjects of the pedagogical methodology called service-learning (hereafter APS) helps students acquire transversal skills that until now have not been sufficiently worked on. I started by putting this into practice in one of the lines of work proposed by the Faculty of Philology of the University of Philology (UDC) for the end-of-degree assignments. In particular, that of "Spanish as a foreign language" (hereafter ELE), which focuses on methodological issues of that area and in which teaching proposals and other aspects related to learning and teaching of ELE are included. One of my students accepted the challenge of designing and putting into practice a didactic unit with adult immigrants in a NGO in A Coruña, Ecodesarrollo Gaia. Many results have been obtained after applying APS: from the improvement of the social and labour integration of immigrants to the achievement of the essential purpose of our University, that is, to be a "qualit y public service aimed at achieving higher levels of welfare for the whole society..."

KEY WORDS: Service-learning; Spanish for immigrants; Spanish teaching for specific purposes; Teaching of Spanish as a second language (EL2). 


\section{INTRODUCCIÓN}

Desde el último decenio de mi trayectoria docente en la Universidad de A Coruña, me he planteado el imperativo moral de que mi trabajo en el área de Lengua Española debe contribuir a mejorar mínimamente la sociedad. A partir de cursos ofrecidos por la Oficina de Cooperación y Voluntariado en colaboración con el CUFIE, surge el proyecto de implementar la técnica aprendizaje y servicio (en adelante, ApS) en Español como Segunda Lengua (en adelante, EL2). En esta materia se presentan aspectos metodológicos de la enseñanza de español como lengua extranjera o segunda lengua; se trata de una asignatura optativa que eligen muchos alumnos de la Facultad de Filología. Asimismo, con un descriptor semejante, se ofrece también una línea para el trabajo fin de grado (TFG). En ambos niveles planteo a los estudiantes la posibilidad de trabajar unidades didácticas (UD) de español para inmigrantes. Únicamente una alumna de las que han elegido realizar el TFG conmigo ha querido aceptar el reto, Zaida Patiño Palleiro. Y esta será la experiencia docente que presento. Se trata de diseñar, llevar a la práctica y evaluar una unidad didáctica de enseñanza de español como segunda lengua (L2) a inmigrantes adultos en la ONGD Ecodesarrollo Gaia con un nivel A2.

Desde hace varios años en las universidades españolas se aplica la metodología pedagógica ApS. Esta innovación docente fusiona, con coherencia y potencia, el aprendizaje de una materia del currículo y el servicio a la comunidad, ya que el alumnado adquiere saberes propios de su formación académica realizando una acción beneficiosa a la sociedad 0 al entorno.

El caso que nos va a ocupar es una ApS solidaria, ya que el servicio que se presta está vinculado a causas solidarias y humanitarias, concretamente está orientado a la cooperación para el desarrollo.

\section{DESCRIPCIÓN DE LA EXPERIENCIA}

El proceso que he seguido en la implementación del proyecto es el siguientei: 
- Dos puntos de partida convergentes: una necesidad social y una materia del currículo con la que puede conectarse.

- Elección del servicio y contacto con el centro receptor de este.

- Formación académica del alumnado.

- Preparación y diseño del proyecto. Producción de materiales.

- Ejecución del proyecto.

- Evaluación del proceso, del resultado y de la metodología ApS.

\subsection{Dos puntos de partida convergentes}

Dado que el ApS es una propuesta integradora, hay que considerar la existencia de dos puntos de partida cuyas proyecciones convergen. Por un lado, uno es la mirada crítica a una necesidad social; por otro, la materia del currículo del alumnado con la que se tiene que poner en relación el servicio. No cabe duda de que los inmigrantes adultos no integrados en la sociedad es un colectivo que vive en una situación precaria y que no puede acceder a una enseñanza reglada del español que le permita optar a trabajos para vivir dignamente. El otro punto de partida es una determinada materia del currículo: se trata del TFG vinculado a una línea de trabajo de enseñanza del español como segunda lengua (EL2).

Al hilo de esto, y para precisar mejor el concepto de ApS, puede servirnos contrastar la intervención que se presenta en este artículo con una actividad de prácticas externas extracurriculares (en adelante, PEE) propuesta por la Facultad de Filología para el grado de Español en el curso 2016-2017. El trabajo en cuestión se ha realizado en la ONGD Viraventos y en la convocatoria se describe así: «Reforzo educativo con nenos/as y adolescentes inmersos en procesos migratorios $"$ iii.

Para entender mejor qué es ApS y qué no es, partamos de los cuadrantes de aprendizaje servicio elaborados por el Service-Learning 2000 Center de la Universidad de Stanford (Service Learning 2000 Center, Service learning Quadrants, Palo Alto, CA, 1996; apud Puig y otros, 2007: 23-25). 


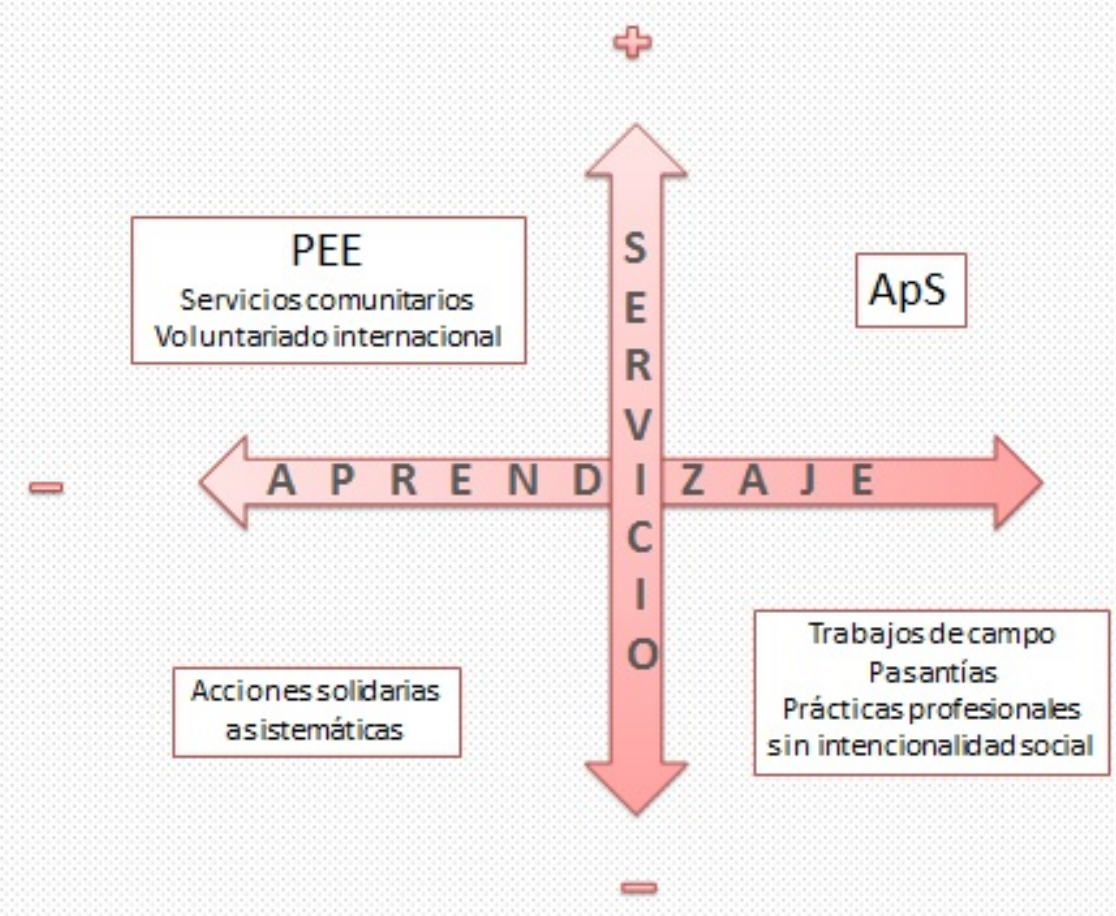

Figura 1. Cuadrante de aprendizaje-servicio.

Como se observa en la figura 1 , se definen cuatro tipologías de actividades atendiendo a dos parámetros: el servicio prestado y la sistematicidad del aprendizaje. En el eje vertical se registra el primer parámetro (mayor arriba y menor 0 inexistente abajo). En el eje horizontal se da cuenta del grado de sistematicidad del aprendizaje (a la izquierda se ubican los aprendizajes asistemáticos y a la derecha, los sistemáticos).

Así pues, en los dos cuadrantes superiores se ubican los proyectos con más servicio -0 de más calidad-, por tanto, las prácticas extracurriculares (PEE) y las experiencias de ApS, frente a las acciones solidarias asistemáticas, por una parte, y los trabajos de campo, por otra, los cuales están en los dos cuadrantes inferiores. Por lo que respecta al parámetro horizontal, en el caso de la PEE - situada a la izquierda-, apenas hay aprendizaje sistemático, mientras que en las experiencias de ApS -a la derecha- sí lo hay. 
En resumen, el Aps se caracteriza por destacar tanto el servicio como el aprendizaje (+ aprendizaje, + servicio), mientras que en las prácticas externas extracurriculares (PEE) el aprendizaje asociado al servicio es mínimo (-aprendizaje, + servicio). En el ApS el proyecto está vinculado explícitamente a una asignatura del currículo, mientras que las PEE no lo están. De hecho, en la oferta de trabajo de la PEE estudiada aquí únicamente se indica que entre los requisitos se piden conocimientos avanzados en gramática del español y en Español como Segunda Lengua (EL2) ${ }^{\text {iv }}$. La evaluación, su sistema y criterios son mucho más complejos en el ApS que en la PEE. En esta hay una evaluación del tutor de prácticas y otra del tutor académico, quien, en el caso de PEE, se limita a revisar la realización de la actividad y dar la acreditación sin calificación cuantitativa. Sin embargo, en el ApS la evaluación es procesual y efectivamente formativa; asimismo, se establecen criterios de evaluación en la guía docente y el resultado final es una calificación numérica.

En conclusión, la metodología que nos interesa en este artículo se caracteriza por que es elevado el nivel de servicio a la comunidad 0 al medioambiente y por que también es un aprendizaje real incardinado en el currículo, ya que, entre otras cosas, está vinculado a una materia determinada y sometido a un sistema de evaluación bien definido.

\subsection{Elección del servicio y contacto con el centro receptor de este}

En el caso de aprendizaje servicio solidario y cooperativo, como es nuestra Aps, los centros receptores del servicio son entidades u organizaciones sociales. El segundo paso era, pues, la elección de la ONGD donde llevar a cabo el proyecto. Fue la Oficina de Cooperación y Voluntariado quienes me pusieron en contacto con una de las ONGD con las que trabaja la Universidad: Ecodesarrollo Gaia. Se trata de una entidad pequeña que está en el barrio coruñés de la Sagrada Familia. Como explican en su página web, nace en 1992 en el marco de la Conferencia de las Naciones Unidas CNUMAD Río-92; su lema es «Honestidad eficazmente solidaria». 
Trabaja en el marco de los Derechos Humanos, la Paz-NoViolencia, la Igualdad de Oportunidades de Género, la Defensa del Medio Ambiente, la Sostenibilidad, la Equidad Norte-Sur y la Equidad Intergeneracional con la inmigración y en proyectos de codesarrollo-cooperación internacional. ${ }^{v}$

\subsection{Formación académica del alumnado}

Como hemos visto supra, en el ApS el aprendizaje es fundamental, de modo que uno de los dos puntos de partida para un proyecto de este tipo es el currículo de nuestro alumnado universitario. En el caso que nos ocupa, la alumna que realizó el TFG ha tenido que formarse en enseñanza de español como segunda lengua (EL2), especialmente en cuestiones de metodología, y, además, en la enseñanza-aprendizaje de un tipo específico de aprendientes: los inmigrantes adultos.

La instrucción de español a inmigrantes se enmarca en la enseñanza con fines específicos (en adelante, EFE), que está tan de moda hoy en día en las aulas de español como EL2. A diferencia de la generalista, la EFE ha de enfocarse hacia las necesidades objetivas o de uso que vayan a tener realmente los aprendientes. Pongamos por caso, quienes quieren aprender español por motivos profesionales necesitarán sobre todo aprender la lengua con el fin de desarrollar actividades de comunicación social propias de su especialidad (esto es, realizar eventos, como una campaña publicitaria) y, por tanto, trabajar con géneros discursivos que se den en esas situaciones comunicativas (como la defensa oral de una idea para la campaña, por ejemplo).

Dentro de la EFE, se pueden distinguir varias ramas en función de los destinatarios de la enseñanza de español (Martín Peris y otros, 2012: 11-12): niños, adolescentes, inmigrantes 0 quienes tienen el español como lengua heredada (son los descendientes de emigrantes que aprenden el castellano por ser de origen familiar).

Los inmigrantes forman un grupo con necesidades específicas determinadas. Se han instalado recientemente en un país de habla hispana en busca de mejores condiciones de vida. Tienen 
que resolver problemas relacionados con las necesidades primarias básicas, como encontrar vivienda, cobertura sanitaria, educación para sus hijos..., y también los relacionados con la gestión de documentación para distintas administraciones. Salvando la precariedad de su situación, sus demandas son las mismas que las de los nuevos residentes, por lo que, según Martín Peris y otros (2012: 12), cabría pensar que el currículo para inmigrantes se ha de integrar en el de nuevos residentes.

Como se defendía en el apartado 2.1., el proyecto realizado con la metodología ApS ha de estar sustentado en la formación académica y, más concretamente, en una asignatura del currículo. En el caso que nos ocupa, se trata del TFG, con el que se pretende que el alumno muestre la adquisición de las competencias más importantes de la titulación. En general, en todos los trabajos finales de carrera se da cuenta de las competencias más académicas, las de tipo $\mathrm{A}$; sin embargo, se descuidan otras más generales y transversales, que sí se reflejan en los proyectos de ApS. El TFG en cuestión sí se ocupa, concretamente, de este tipo de competencias ${ }^{\mathrm{vi}}$ :

Competencias del título básicas/generales (tipo B):

B9: Valorar la importancia que tiene la investigación, la innovación y el desarrollo tecnológico en el avance socioeconómico y cultural de la sociedad.

B10: Comportarse con ética y responsabilidad social como ciudadano/a y profesional.

Competencias del título transversales o nucleares (tipo C):

C4: Desarrollarse para el ejercicio de una ciudadanía abierta, culta, crítica, comprometida, democrática y solidaria, capaz de analizar la realidad, diagnosticar problemas, formular e implantar soluciones basadas en el conocimiento y orientadas al bien común. 
C8: Valorar la importancia que tiene la investigación, la innovación y el desarrollo tecnológico en el avance socioeconómico y cultural de la sociedad.

\subsection{Diseño del proyecto. Producción de materiales}

Cuando se diseña un proyecto docente es fundamental centrarse desde el comienzo en el alumno y conocer los factores personales que inciden en el aprendizaje, en este caso, de una lengua (edad, aptitud, motivación, estilos de aprendizaje...). Y esto ha de suceder más aún en una metodología de ApS, ya que en el servicio a una comunidad necesitada hemos de acercarnos al otro con más delicadeza, respeto y empatía, si cabe, que con otro colectivo en situación muy distinta.

El grupo con el que la alumna ha trabajado constaba de siete aprendientes, senegaleses y marroquíes de entre 20 y 32 años, de entre los cuales cinco eran mujeres. Su nivel de formación era muy heterogéneo: una tenía estudios universitarios; cuatro, secundarios, y dos, primarios. En relación con las lenguas que hablaban, había también variedad: las cuatro alumnas senegalesas hablan wolof y francés, y una de ellas, la universitaria, también inglés; los tres alumnos marroquíes solo tenían como primera lengua el árabe. En general, unos y otros dominaban más el español oral que el escrito y que la gramática, de hecho, sus destrezas orales estaban en un nivel B1, mientras que tenían dificultad para cumplimentar cuestionarios, por ejemplo. Con relación a las motivaciones, eran muy distintas: varias mujeres querían aprender para ayudar a sus hijos en las tareas escolares, otra para conseguir trabajo con el que contribuir a la economía familiar, los hombres deseaban aprender a hacer sus propios currículos.

Tal y como se indica en la bibliografía de español para fines específicos, es necesario que el profesor de estos estudiantes realice un análisis de necesidades objetivas o de uso de los aprendientes. En el caso que nos ocupa, no había duda de que lo que urgía era darles herramientas lingüísticas para conseguir un trabajo, lo que implica dominar el vocabulario de 
las profesiones a las que tendrían acceso en un primer momento, comprender anuncios de oferta y demanda de empleo, escribir su propio currículum, comprender modelos de carta de presentación y familiarizarse con aspectos de la cultura española.

Como se ve en la figura 2 (v. infra), en la fase del diseño de la ApS, la clave está en la comunicación multidireccional del trabajo en red (De la Cerda y otros, 2009: 31): entre el profesor universitario y el estudiante del TFG, de ambos con el centro receptor, del alumno con los aprendientes receptores del servicio, y de estos con la institución adonde acuden.

\section{Comunicación multidireccional}

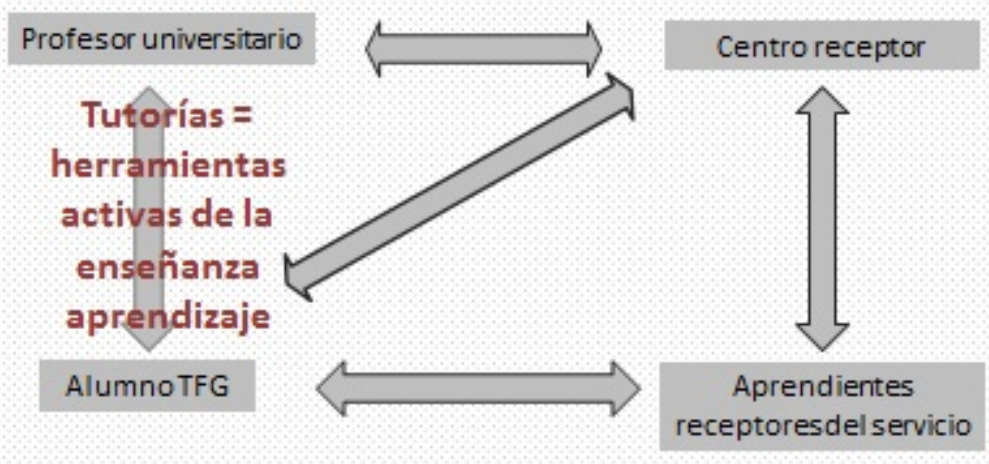

Figura 2. Trabajo en red en el aprendizaje-servicio.

Las relaciones entre el docente y el universitario tienen lugar en las frecuentes tutorías que se mantienen. No cabe duda de que en esta metodología se potencia especialmente la atención personalizada al alumno que realiza el TFG. Estos encuentros de trabajo se convierten, así, en una herramienta activa del proceso de enseñanza-aprendizaje, en la que el profesor es guía, orientador, pero sobre todo interlocutor del estudiante que ya es casi un egresado.

Con relación a la producción de materiales, el docente ha de ser un lector objetivo y un corrector crítico. En el caso que nos ocupa, la alumna realizó un magnífico TFG, al que anexó un completo cuadernillo de la unidad didáctica (UD), con el fin de que los aprendientes 
trabajasen con este documento. Es un material didáctico creativo y visual, que capta la atención de los inmigrantes y los motiva, y que fue también muy bien valorado por el tribunal.

\subsection{Ejecución del proyecto}

La actividad docente se efectuó en seis sesiones, de 90 minutos cada una, distribuidas a lo largo de dos semanas en días alternos; se realizó la tercera y cuarta semana de abril del curso académico 2014-2015. Previamente, como se indicó supra, la autora del TFG había hecho un análisis de necesidades para el cual se pasó un cuestionario a todos los aprendientes y también se llevaron a cabo entrevistas personales durante los días previos.

El método que se siguió para desarrollar el proyecto fue ecléctico, pero coherente, basado en la concepción del alumno como un agente social, esto es, según esta perspectiva, el aprendiente ha de poder ser capaz de comunicarse y de realizar acciones en las interacciones sociales que se proponga (MCERL, 9; PCIC, «Perspectiva del alumno: Ios objetivos generales»).

Para realizarlo se basó en el enfoque por tareas sin descuidar la formación gramatical de los aprendientes.

Una tarea se define como cualquier acción intencionada que un individuo considera necesaria para conseguir un resultado concreto en cuanto a la resolución de un problema, el cumplimiento de una obligación o la consecución de un objetivo. [...] la realización de estas tareas supone llevar a cabo actividades de lengua y necesita el desarrollo de textos orales o escritos (mediante la comprensión, la expresión, la interacción y la mediación) (MCER, 9 y 15).

Por ejemplo, en el caso que nos ocupa, la tarea final es la entrega de un currículum y la realización de una entrevista laboral. Como se deduce, en este enfoque la tarea es el eje vertebrador del aprendizaje: es el punto de partida del diseño, porque determina los contenidos 
de una unidad didáctica y los demás elementos de su programación (Estaire, 2007, 2011), y el punto final de su ejecución.

\section{RESULTADOS}

Los alumnos de la ONGD adquirieron formación en español imprescindible para el acceso al mundo laboral. De hecho, al final del curso, cada uno de ellos superó satisfactoriamente la entrevista de trabajo que simularon con la profesora. También avanzaron en la escritura en español, llegaron a cumplimentar perfectamente un currículum.

Asimismo, los aprendientes demostraron haber adquirido otras competencias como el aprendizaje cooperativo y la capacidad intercultural. Aquel surgió de una forma espontánea, incluso la ayuda se llevó a cabo entre hombres y mujeres que provenían de sociedades y culturas en las que no hay igualdad de género. Por su lado, la interculturalidad implica que el estudiante de español trate de identificar los estereotipos culturales y romperlos; de buscar la relación entre las distintas culturas, sus puntos de encuentro y sus diferencias, y de hacer el esfuerzo de comprenderlas. Esto por lo que se refiere al conocimiento intercultural. Por lo que respecta a las destrezas, son la capacidad de adaptarse, interactuar y desenvolverse con éxito en distintas situaciones en las que el aprendiente se relaciona con personas de comunidades diferentes a la suya y también la habilidad de hacer de intermediario cultural. Las actitudes interculturales son la apertura hacia la cultura del otro y sus motivaciones, son el interés y la empatía hacia ella (PCIC, «Habilidades y actitudes interculturales. Introducción»).

Tras finalizar la ejecución del proyecto, es también momento de analizar el proceso seguido en esta ApS. Al respecto, Ios resultados de la evaluación de cada una de las fases de la actividad son los siguientes.

a) Dos puntos de partida convergentes. En este proyecto ha habido una conexión óptima entre una necesidad social y una materia del currículo. La deficiencia en la comunicación en español de personas que tienen necesidad vital de aprenderlo, pero que carecen de medios para hacerlo es el servicio idóneo para un especialista en 
lengua y literatura españolas interesado por la docencia de español como segunda lengua (EL2). Y la asignatura del trabajo fin de grado (TFG) ofrecía el mejor marco curricular en el que fundamentar académicamente el servicio.

\section{b) Elección del servicio y contacto con el centro receptor de este}

El personal de Ecodesarrollo Gaia que nos atendió colaboró muy estrechamente con nosotras; realmente trabajamos con ellos en red. Así pues, el paternariado creado fue óptimo.

En relación a las ONGD en general y a esta en particular, debo dejar constancia de que las clases de EL2 se dejan en manos de personas que, aunque tienen muy buena voluntad, les falta formación para impartirlas. Suelen ser asistentes sociales, educadores sociales, buenos profesionales en su campo, pero no para la EEL2.

\section{c) Formación académica del alumnado}

Para un especialista en lengua y literatura que oriente su carrera profesional a la docencia, es necesario no solo formarse en la disciplina que va a impartir, sino también el conocimiento de sus futuros discípulos, máxime en una práctica de este estilo en la que es tan relevante conocer la situación social y psicológico-afectiva de los inmigrantes adultos. Pero no es competencia de unos estudios no profesionalizantes como los grados en Estudios Lingüísticos y Literarios, por lo que esta carencia se palió con la sensibilidad y empatía de la alumna hacia el colectivo de inmigrantes, el buen quehacer de esta y la ayuda prestada por los responsables de la ONGD Ecodesarrollo Gaia. Así pues, el proyecto que llevamos a cabo podría haberse enriquecido con formación en materias como psicología.

d) Preparación y diseño del proyecto. Producción de materiales

Como ya se puso de manifiesto, un buen análisis de necesidades es la clave del éxito de la enseñanza de español con fines específicos. En este caso, se hizo con rigor y profundidad, de modo que desde el principio la futura graduada ya conocía de antemano la heterogeneidad del grupo. A partir del análisis se diseñó el proyecto, que 
fue modificándose durante el servicio al recibir retroalimentación de los aprendientes, lo que, sin duda, mejoró la intervención educativa. El resultado de este proyecto es el TFG de la alumna Zaida Patiño Palleiro, que mereció la valoración de sobresaliente.

\section{e) Ejecución del proyecto}

He de valorar favorablemente el proyecto ejecutado. Resultó muy útil y motivador organizar la intervención docente en función de la tarea final. También fue muy positivo fomentar el aprendizaje cooperativo entre hombres y mujeres. Las cuestiones de interculturalidad resultaron ser un complemento muy importante de la formación lingüística. No obstante, hay que decir que los inmigrantes necesitarían una enseñanza de EL2 continuada e impartida por profesionales como los egresados de la Facultad de Filología.

\section{CONCLUSIONES}

La experiencia de Aps expuesta permite evaluar también la metodología seguida, teniendo en cuenta que aquí se realizará una valoración a partir de una única muestra.

Desde el punto de vista del docente, estos proyectos suponen una gran carga de trabajo por cuestiones de gestión, por la coordinación con el centro implicado, por la dirección y el seguimiento individualizado de la actividad. Resulta muy difícil llevarlo a cabo en asignaturas con muchos alumnos matriculados y en los dos primeros cursos del grado; en primer lugar, por la dificultad de su ejecución y por la complicación en la tutorización de la actividad; además, a estos niveles, en general, a los estudiantes les falta formación académica, reflexión crítica profunda y casi completa autonomía en el trabajo. Por otra parte, dado que, en general, no es una metodología generalizada en las universidades españolas, el profesor que la pone en práctica se encuentra solo y, por supuesto, resulta muy difícil llevarla a cabo como un trabajo transversal interdisciplinar.

No obstante, el ApS es una propuesta integradora, que conecta los conocimientos académicos del profesor con la realidad social y que le permite trabajar en red con centros externos a la 
Universidad (Palos Rodríguez, 2009: 157). También favorece la interacción con el estudiante, lo que resulta motivador para el docente. Y lo que a mi modo de ver son las cuestiones más importantes: por un lado, es una propuesta creativa y eficaz para desarrollar el aprendizaje del estudiante, con lo que se consigue con provecho nuestro objetivo docente ${ }^{\text {vii }}, y$, por otro lado, responde a un llamamiento ético y moral que todos tenemos como personas y ciudadanos ${ }^{\text {viii }}$. Desde el punto de vista del alumno, también él tiene más carga de trabajo. Pero, en contrapartida, mejora su aprendizaje académico, ya que afianza conocimientos y procedimientos adquiridos. Le permite poner en práctica su formación disciplinar y en situaciones más difíciles que en un entorno profesional normal. Y es que, como afirma Palos Rodríguez (2009: 157), el entorno «tiene una función educativa importante». Además, a los especialistas en lengua y literatura les ayuda a vislumbrar lo que posiblemente será su futura profesión, la docencia. También, desarrolla las competencias básicas que normalmente se dejan de lado, por ejemplo, la de ser ciudadanos activos y críticos. Genera vivencias en muchos casos impactantes que quizá marquen para toda la vida; desarrolla la inteligencia emocional y social de individuo. Para el estudiante, es un desafío personal cumplido, lo que produce satisfacción personal.

Por lo que se refiere a los receptores del servicio, se benefician de la intervención de los universitarios; en el caso que nos ocupa, con las clases de EL2 se ha contribuido, aunque sea mínimamente, a la integración de los inmigrantes en la nueva comunidad. No cabe duda de que el beneficio sería mayor si las actividades fuesen más continuadas en el tiempo. Por otro lado, la entidad receptora se visibiliza en el mundo académico.

Para finalizar, a partir de mi experiencia concreta en la aplicación de la metodología ApS en el ámbito universitario, se pueden extraer las siguientes conclusiones:

- Los profesores universitarios debemos actuar como personas y ciudadanos activos y críticos, pero también solidarios. 
- Es mejor aplicar esta metodología en asignaturas de tercer curso y cuarto 0 en másteres, y en materias de poco alumnado.

- Es conveniente que el profesorado trabaje en equipos interdisciplinares.

- Las actividades de ApS deben durar más que la explicada, preferiblemente un cuatrimestre completo, con el fin de que el servicio no quede interrumpido.

- Estas actividades curriculares requieren el fortalecimiento de las tutorías.

Con este tipo de metodología docente se hace realidad la finalidad que se plantea nuestra Universidadix:

Forma parte de la misión de la Universidade da Coruña la formación de una ciudadanía abierta, culta, crítica, comprometida, democrática, cooperativa y solidaria, capaz de analizar la realidad, diagnosticar problemas, plantear e implantar soluciones basadas en el conocimiento y orientadas al bien común.

\section{REFERENCIAS}

- Amat, F. \& otros (2011). Aprendiendo a transformar el entorno: el uso del aprendizaje servicio en la educación superior. Castelló de la Plana: Universitat Jaume I, Servei de $\begin{array}{lllll}\text { Comunicació } & \text { i } & \text { Publicacions. } & \text { línea }\end{array}$ https://es.slideshare.net/upnpedagogica/aprendiendo-a-transformar-el-entornoeducacion-superior. (Fecha de consulta: 12.10.2017).

- Batlle, R. (2009). El servicio en el aprendizaje servicio. En J. M. Puig, (coord.), Aprendizaje servicio (ApS). Educación y compromiso cívico (pp. 71-90). Barcelona: Graó.

- De la Cerda, M. \& otros (2009). Aprendizaje servicio: ejemplos y definiciones. En J. M. Puig, (coord.), Aprendizaje servicio (ApS). Educación y compromiso cívico (pp. 15- 32). Barcelona: Graó. 
- Estaire, S. (2007). La enseñanza de lenguas mediante tareas: principios y planificación de unidades didácticas. En línea, en https://es.scribd.com/document/271832296/LA-ensenanza-de-lenguas-mediantetareas-principios-y-planificacio-n-de-ud. (Fecha de consulta: 4.11.2017).

- Estaire, S. (2011). Principios básicos y aplicación del aprendizaje mediante tareas. MarcoELE, 12, pp. 1-26. En línea en http://marcoele.com/descargas/12/estairetareas.pdf (Fecha de consulta: 25.2.2012).

- Marco común europeo de referencia para las lenguas, versión en español. En línea en https://cvc.cervantes.es/ensenanza/biblioteca_ele/marco/cvc_mer.pdf. (Fecha de consulta: 23.10.2017). (MCERL).

- Martín Peris, E.; Sabater Torres, M. ${ }^{a}$ L., \& García Santa-Cecilia, Á. (2012). Guía para el diseño de currículos especializados. Madrid: Instituto Cervantes.

- Martín, X, (2009). Aprendizaje en el aprendizaje servicio. En J. M. Puig, (coord.), Aprendizaje servicio (ApS). Educación y compromiso cívico (pp. 107-126). Barcelona: Graó.

- Palos Rodríguez, J. (2009): ¿Por qué hacer actividades de aprendizaje servicio? En J. M. Puig, (coord.), Aprendizaje servicio (ApS). Educación y compromiso cívico (pp. 151-161). Barcelona: Graó.

- Plan curricular del Instituto Cervantes, en línea en https://cvc.cervantes.es/ensenanza/biblioteca_ele/plan_curricular/default.htm. (Fecha de consulta: 23.10.2017). (PCIC).

- Puig, J. M.; Battle, R.; Boch, C., \& Palos, J. (2007): Aprendizaje servicio. Educar para la ciudadanía. Barcelona: Octaedro.

- Puig, J. M. (coord.) (2009). Aprendizaje servicio (ApS). Educación y compromiso cívico. Barcelona: Graó. 
Página web de la UDC. Sobre la UDC. Presentación de la Universidad. (En línea en http://www.udc.es/sobreUDC/index.html?language=es; fecha de consulta: 17.11.2017).

ii Lo he adaptado de Puig (2009: 26, 69-139) y de Amat, Francisco y otros (2011).

iii En línea, en http://www.udc.es/export/sites/udd/filo/_galeria_down/practicas_graos/2016_2017/Niraventos_PEG-81617.pdf; fecha de consulta: 17.10.2017.

${ }^{i v}$ Regulamento de prácticas académicas externas do estudantado da Universidade da Coruña. Aprobado en Consello de Gobemo de data 23 de abril de 2013 e modificado polo acordo do Consello de gobemo do 27 de febreiro do 2015. (En línea en https:/www.udc.es/export/sites/udc/practicasextemas/_galeria_down/Regulamento.pdf; fecha de consulta: 18.11.2017).

$\checkmark$ Página web de Ecodesarrollo Gaia. (En línea, en https://ecodesarrollogaia.org/; fecha de consulta: 11.12.2017).

vi Asignatura: Traballo Fin de Grado. Competencias do título. (En línea en https://guiadocente.udc.es/guia_docent/index.php?centre $=613 \&$ ensenyament $=613 \mathrm{G} 01$ \&assignatura $=$ 613G01041\&fitxa_apartat $=1 \&$ any_academic $=2017$ _18\&idioma $=$ cast\&idioma_assig $=$ \&any_academi C=2017_18; fecha de consulta: 17.11.2017).

vii «La decisión de llevar a cabo este tipo de actividades [...] responde a un cuestionamiento del para qué, del qué y del cómo educar» (Palos Rodríguez, 2009: 160).

viii «El aprendizaje-servicio apunta a un concepto de educación que pretende transformar la sociedad y no solo mejorar las capacidades de las personas» (Battle, 2013: 143).

ix Documento para el Plan Estratégico 2013-2020, aprobado por el Consejo de Gobierno del 21 de marzo de 2013 y sometido al Claustro del 30 de abril de 2013, «Misión, visión y valores da UDC».

(En línea en http://www.udc.es/sobreUDC/mision/index.html?language=es; fecha de consulta: 17.11.2017). 